\title{
Common Transcriptional Signatures in Brain Tissue from Patients with HIV-Associated Neurocognitive Disorders, Alzheimer's Disease, and Multiple Sclerosis
}

\author{
Alejandra Borjabad • David J. Volsky
}

Received: 25 April 2012 / Accepted: 26 September 2012 /Published online: 12 October 2012

(C) Springer Science+Business Media New York 2012

\begin{abstract}
HIV-Associated Neurocognitive Disorders (HAND) is a common manifestation of HIV infection that afflicts about $50 \%$ of HIV-positive individuals. As people with access to antiretroviral treatments live longer, HAND can be found in increasing segments of populations at risk for other chronic, neurodegenerative conditions such as Alzheimer's disease (AD) and Multiple Sclerosis (MS). If brain diseases of diverse etiologies utilize similar biological pathways in the brain, they may coexist in a patient and possibly exacerbate neuropathogenesis and morbidity. To test this proposition, we conducted comparative meta-analysis of selected publicly available microarray datasets from brain tissues of patients with HAND, AD, and MS. In pair-wise and three-way analyses, we found a large number of dysregulated genes and biological processes common to either HAND and AD or HAND and MS, or to all three diseases. The common characteristic of all three diseases was up-regulation of broadly ranging immune responses in the brain. In addition, HAND and AD share down-modulation of processes involved, among others, in synaptic transmission and cell-cell signaling while HAND and MS share defective processes of
\end{abstract}

Electronic supplementary material The online version of this article (doi:10.1007/s11481-012-9409-5) contains supplementary material, which is available to authorized users.

A. Borjabad · D. J. Volsky $(\bowtie)$

Molecular Virology Division, St. Luke's-Roosevelt Hospital Center, Columbia University,

432 West 58th Street, Antenucci Building, Room 709,

New York, NY 10019, USA

e-mail: djv4@columbia.edu

A. Borjabad

e-mail: ab2612@columbia.edu

A. Borjabad · D. J. Volsky

Department of Pathology \& Cell Biology, Columbia University,

New York, NY 10032, USA neurogenesis and calcium/calmodulin-dependent protein kinase activity. Our approach could provide insight into the identification of common disease mechanisms and better intervention strategies for complex neurocognitive disorders.

Keywords Transcriptome meta-analysis · Microarrays · HIV · HAND · Alzheimer's disease · Multiple sclerosis

\section{Introduction}

HIV infection can cause a wide spectrum of central nervous system (CNS) complications ranging from mild neurocognitive impairments to incapacitating dementias that have been recently grouped under the term HIV-associated neurocognitive disorders or HAND (Antinori et al. 2007). Historically, HIVassociated dementia (HIV-D or HAD) was the most prominent manifestation of HIV-mediated brain disease (Epstein et al. 1986; Navia and Price 1987). The introduction of highly efficacious antiretroviral therapies (ART) has markedly reduced the prevalence of HAD but it has had a limited effect on the two other major manifestations of HAND, the HIV-associated asymptomatic neurocognitive impairment (ANI) and the HIVassociated mild neurocognitive disorder (MND) (Sacktor et al. 2002; Ellis et al. 2007; Robertson et al. 2007). By some accounts, up to $50 \%$ of HIV-infected individuals will develop some form of neurocognitive impairment despite access to ART (Ellis et al. 2007; Heaton et al. 2010; Simioni et al. 2010; Harezlak et al. 2011). As HIV infection has become a chronic and manageable condition under ART (Richman 2001), the populations at risk of HAND may begin overlapping with populations prone to other chronic diseases of the central nervous system such as AD (Alisky 2007; Pulliam 2009) and MS (Berger et al. 1992; Lackner et al. 2010). If brain diseases of diverse etiologies utilize common biological pathways in the 
nervous system, coexistence of such pathologies in a patient may lead to increased morbidity. On the other hand, identification of such common pathogenic pathways may suggest common therapeutic approaches to diverse diseases.

A number of commonalities between HAND and other neurodegenerative diseases were revealed by studies of individual disease determinants. For example, in some patients HIV infection was shown to correlate with the presence of leukoencephalomyelopathy and MS-like illness (Berger et al. 1992; Corral et al. 2004). In a recent crosssectional cohort study, HAND was shown to correlate with presence of auto-antibodies to myelin oligodendrocyte glycoprotein, including in patients on ART with suppressed plasma HIV (Lackner et al. 2010), suggesting that HAND and MS neuropathogenesis may overlap in the pathway of aberrant myelin breakdown. Consistent with this finding, our recent microarray analysis of brain tissues from HAND patients on ART revealed significant downmodulation of several myelin metabolism-related genes including myelin-associated oligodendrocyte basic protein (MOBP), myelin transcription factor 1 (MYT1) and myelin basic protein (MBP) (Borjabad et al. 2011). On the other hand, HIV Tat was shown to inhibit neprilysin and elevate amyloid-beta in fetal human brain spheres in culture and amyloid-beta was elevated in postmortem brain tissues of patients with HAND (Rempel and Pulliam 2005), suggesting one common pathway in HAND and AD pathogenesis in older individuals. This notion is supported by recent proteomic analysis of postmortem frontal cortex tissues from HIV positive patients with or without HAD, which revealed aberrant expression of proteins involved in glycolysis and oxidative phosphorylation specifically in HAD tissues and noted similar pathway changes in other dementia conditions including Alzheimer's and Parkinson's diseases (Zhou et al. 2010). Broader patterns of similarity between HAND and diseases such as AD and MS were suggested based on review of macrophage/microglia and astrocyte functions in neuropathogenesis (Minagar et al. 2002), review of dysregulation of specific genes in these pathologies (Minagar et al. 2004), and bioinformatics-aided analysis of potential parallels in chromosomal localization, expression and function of dementia-associated genes between HAND and AD (Shapshak et al. 2008). Indeed, a recent review by Noorbakhsh et al. presented a convincing case for the power of integrative analysis of data-rich studies involving functional genomics, proteomics, and other systems biology approaches in discerning convergent pathways of human neuropathogenesis (Noorbakhsh et al. 2009).

In the present study we used publicly available functional genomic data and bioinformatics tools to conduct for the first time a comparative analysis of gene expression profiles of brain tissues of HAND, AD, and MS. Genome-wide microarray analysis of coordinated changes in gene expression is one of the most established platforms for integrated understanding of global phenotypic changes occurring during transition from normal to pathological states, including in the central nervous system (D'Agata and Cavallaro 2004; Grunblatt 2004; Blalock et al. 2005; Noorbakhsh et al. 2009; Bossers et al. 2010; Cooper-Knock et al. 2012). Our objective was to identify altered gene expression motifs in brain tissues that may indicate convergence of pathogenic mechanisms driving development of HAND and one or both of the other two neurodegenerative conditions in this study. A rich microarray database from multiple studies exists for AD and MS (for reviews, see (Katsel et al. 2005; Lindberg and Kappos 2006; Tajouri et al. 2007; Kinter et al. 2008)). The respective database from HAND brain tissues is less extensive but it nevertheless encompasses analyses of over 60 HAND patients and controls in five studies (Gelman et al. 2004; Masliah et al. 2004; Shapshak et al. 2004; Everall et al. 2005; Borjabad et al. 2011). The meta-analysis of these datasets revealed numerous aberrant gene expression changes and alterations in biological pathways that were common to HAND and AD and HAND and MS in two-way analyses, and that were overlapping for all three diseases in a three-way comparison.

\section{Materials and methods}

Selection of gene expression datasets from brain tissues of individuals with HAND, AD, and MS for comparative analysis

The microarray studies of the three neurodegenerative diseases of interest were identified through search of publicly available gene expression databases, primarily PubMed and Gene Expression Omnibus (GEO) at the National Center for Biotechnology Information (NCBI) (http://www.ncbi.nlm. nih.gov/). The studies selected for this work are listed in Tables 1 and 2. We considered only microarray studies conducted with human post-mortem brain tissue, excluding animal and tissue culture models of these diseases. The choice of brain anatomical regions included in our analyses is explained in Results. To facilitate comparison among diverse microarray datasets only studies that used control groups and expressed results as differential gene expression (fold change) between tested biological state and control were selected. Finally, we excluded studies that provided insufficient information about microarray analysis.

Meta-analysis of gene expression profiles

The microarray datasets selected for the current analysis were obtained on various microarray platforms that used different experimental protocols and analytical methods 
Table 1 Published gene expression profiles from HAND brain tissues used in the present analysis

\begin{tabular}{lllll}
\hline Author & Year & Brain area tested & Microarray platform & Biological states compared \\
\hline Masliah & 2004 & Frontal cortex & Affymetrix U95Av2 & HIVE vs non HIVE \\
Gelman & 2004 & Frontal cortex and white matter & Affymetrix HG-U133 & HAND-MCMD-NPI-O vs HIV neg \\
Shapshak & 2004 & Frontal cortex & Affymetrix U95Av2 & HIV vs HIV neg \\
Everall & 2005 & Frontal cortex & Affymetrix U95Av2 & HIVE vs non HIVE \\
Borjabad & 2011 & Frontal lobe white matter & Affymetrix HG-U133 & untreated HAND vs HIV neg \\
Borjabad & 2011 & Frontal lobe white matter & Affymetrix HG-U133 & treated HAND vs HIV neg \\
5 papers: & 1132 up-regulated and 779 down-regulated genes & & \\
\hline
\end{tabular}

(for example, (Masliah et al. 2004; Stephens et al. 2006; Bossers et al. 2010)); the microarray platforms are listed in Tables 1 and 2. To overcome the difficulty inherent in comparing raw microarray datasets from a variety of sources (Tan et al. 2003; Parmigiani et al. 2004; Borjabad et al. 2010), we elected to use second-level derivative datasets representing statistically significant changes in gene expression for each disease under study. Such changes are calculated according to widely acceptable standards for defining statistical significance of differential gene expression (Blalock et al. 2005; Hoheisel 2006) and thus this approach allowed us to compare various datasets independently of microarray platform or statistical approach used. To further facilitate comparison of genes listed by various sources, we standardized gene nomenclature in the present work to GenBank gene symbol identifiers (http://www.ncbi.nlm. nih.gov/genbank/). This permitted us to overcome the inconsistencies of gene nomenclature and to normalize gene identity across the datasets. It should be noted that some of the genes listed in the present analysis have a different gene ID than in the original report as a result of public database updates. Following these preparatory analyses, we pooled the sets of differentially expressed genes listed in each publication within each brain disease group (HAND, treated HAND, AD, and MS). Because our purpose was to generate a comprehensive, brain disease-specific transcriptome incorporating multiple independent studies, we listed each significantly aberrant gene in a given disease group only once and did not assign to genes any additional value besides direction of dysregulation, regardless of whether they were listed in one or multiple publications. The HAND, AD, and MS profiles were then compared in two-way and three-way analyses using the Microsoft database management system Access software to identify common (overlapping) genes. The final common gene datasets were then analyzed by functional categorization of gene families using gene ontology program Expression Analysis Significance Explorer (EASE) (Hosack et al. 2003) (http://david.abcc.ncifcrf.gov/) and the Affymetrix NetAffx ${ }^{\mathrm{TM}}$ Analysis Center (http://www. affymetrix.com/analysis/index.affx).

\section{Results}

Brain transcriptome profiles in HAND and ART-HAND

As of this writing, five published reports employed functional genomics to examine gene expression profiles in brain tissues from patients who died with HAND (Gelman et al. 2004; Masliah et al. 2004; Shapshak et al. 2004; Everall et al. 2005; Borjabad et al. 2011); these reports are listed in Table 1. The Table also provides information on the anatomical brain region and microarray platforms used, and the biological states compared in each study. Three studies examined gene expression patterns in the frontal cortex; one study tested both cortex and subcortical white matter, and one study focused on deep white matter from the frontal lobe region. Three studies used the Affymetrix U95Av2 microarray platform and two were conducted with the new-generation Affymetrix HG-U133 platform. Two HAND array studies used in our analysis show relatively limited sets of gene expression data focusing on the specific HAND disease pathology of HIV-associated encephalitis, HIVE (Masliah et al. 2004; Everall et al. 2005). The initial HIVE analysis employed datasets from HAD patients without HIVE as controls (no HIV negative controls were used), and it identified a total of 133 differentially expressed genes specific to HIVE (Masliah et al. 2004). A follow-up study in the same patient cohort stratified microarray datasets by patient methamphetamine addiction, demonstrating a strong correlation between drug use and induction of interferonrelated genes (Everall et al. 2005). Additional studies based on HIVE-specific datasets were not included because they focus on individual genes already represented in these arrays rather than new array analyses (Everall et al. 2006; Salaria et al. 2007). Two other studies listed in Table 1 (Gelman et al. 2004; Shapshak et al. 2004) examined HIV-infected versus uninfected brain tissues; although these works show only partial datasets or derivative analyses they were included to increase the power of our analysis. The most recent study listed in Table 1 (Borjabad et al. 2011) analyzed postmortem HAND brain tissue versus HIV negative controls; patient 
Table 2 Published gene expression profiles from AD and MS brain tissues used in the present analysis

\begin{tabular}{|c|c|c|c|c|}
\hline Author & Year & Brain area tested & Microarray platform & Biological states compared \\
\hline \multicolumn{5}{|c|}{ Alzheimer's disease } \\
\hline Hata & 2001 & Hippocampus & $\begin{array}{l}\text { Incyte Pharmaceuticals, } \\
\text { UniGem V microarray }\end{array}$ & $\mathrm{AD}$ vs non $\mathrm{AD}$ \\
\hline Loring & 2001 & Amygdala/cingulate cortex & Incyte Genomics, Unigene Lifearray & $\mathrm{AD}$ vs non $\mathrm{AD}$ \\
\hline $\mathrm{Ho} /$ Pasinetti & 2001 & Cortex & $\begin{array}{l}\text { Incyte Pharmaceuticals, } \\
\text { UniGem V microarray }\end{array}$ & early/moderate $\mathrm{AD}$ vs non $\mathrm{AD}$ \\
\hline Colangelo & 2002 & Hippocampus CA1 & Affymetrix U95A & $\mathrm{AD}$ vs non $\mathrm{AD}$ \\
\hline Walker & 2004 & Frontal Cortex & $\begin{array}{l}\text { The Microarray Center, University } \\
\text { Health Network, Toronto }\end{array}$ & $\mathrm{AD}$ vs non $\mathrm{AD}$ \\
\hline Ricciarelli & 2004 & Frontal Cortex & $\begin{array}{l}\text { Clontech, Atlas Human } 12 \mathrm{~K} \\
\text { Microarray }\end{array}$ & $\begin{array}{l}\mathrm{AD} \text { vs non } \mathrm{AD} \text { with amyloid } \\
\text { plaques }\end{array}$ \\
\hline Lukiw & 2004 & Hippocampus & Affymetrix U95A & fetal - adult - AD \\
\hline Small & 2005 & Entorhinal cortex/dentate gyrus & Affymetrix HG-U133 & $\mathrm{AD}$ vs non $\mathrm{AD}$ \\
\hline Emilsson & 2006 & Frontal Cortex & $\begin{array}{l}\text { Uppsala University and Royal } \\
\text { Institute of Technology }\end{array}$ & $\mathrm{AD}$ vs non $\mathrm{AD}$ \\
\hline Parachikova & 2007 & Frontal Cortex/Hippocampus & Affymetrix U95A & $\begin{array}{l}\text { mild-moderate } \mathrm{AD} \text { vs non } \mathrm{AD} \\
\text { high pathology }\end{array}$ \\
\hline Katsel & 2007 & 17 regions & Affymetrix HG-U133 & different stages $\mathrm{AD}$ vs non $\mathrm{AD}$ \\
\hline Brooks & 2007 & Hippocampus & Affymetrix HG-U133 & metabolic genes \\
\hline Weeraratna & 2007 & $\begin{array}{l}\text { Parietal lobes Agilent Human } \\
44 \mathrm{~K} \text { microarray }\end{array}$ & $\begin{array}{l}\text { late } \mathrm{AD} \text { vs non- } \mathrm{AD} \text { dementia } \\
\text { or non } \mathrm{AD}\end{array}$ & \\
\hline Grünblatt & 2007 & $\begin{array}{l}\text { Hippocampus, } \\
\text { gyrusfrontalismedius, } \\
\text { cerebellum }\end{array}$ & Affymetrix HG-U133 & $\mathrm{AD}$ and $\mathrm{PD}$ vs non $\mathrm{AD}$ non $\mathrm{PD}$ \\
\hline Katsel & 2009 & 15 regions & Affymetrix HG-U133 & $\begin{array}{l}\text { youngest-old/oldest-old } \mathrm{AD} \\
\text { and non } \mathrm{AD}\end{array}$ \\
\hline Williams & 2009 & $\begin{array}{l}\text { Synaptoneurosomes from } \\
\text { Prefrontal Cortex }\end{array}$ & Affymetrix HG-U133 & incipient $\mathrm{AD}$ vs non $\mathrm{AD}$ \\
\hline Tan & 2010 & Neocortex (temporal cortex) & $\begin{array}{l}\text { Affymetrix GeneChip Human } \\
\text { Exon 1.0 ST Arrays }\end{array}$ & $\mathrm{AD}$ vs non $\mathrm{AD}$ \\
\hline Bossers & 2010 & Prefrontal Cortex & Agilent Human 44K microarray & comparison different $\mathrm{AD}$ stages \\
\hline \multicolumn{5}{|c|}{18 papers: 5185 up-regulated and 3684 down-regulated genes } \\
\hline \multicolumn{5}{|c|}{ Multiple sclerosis } \\
\hline Whitney & 1999 & White matter & Custom-made cDNA microarrays & $\begin{array}{l}\text { acute lesions vs normal white } \\
\text { matter }\end{array}$ \\
\hline Lock & 2002 & White matter & $\begin{array}{l}\text { Affymetrix HuGeneFL } 7026 \\
\text { microarrays }\end{array}$ & $\begin{array}{l}\text { MS active or silent lesions } \\
\text { vs control }\end{array}$ \\
\hline Tajouri & 2003 & White matter & $\begin{array}{l}\text { Custom-made fluorescent cDNA } \\
\text { microarrays }\end{array}$ & $\begin{array}{l}\text { MS chronic or acute lesions } \\
\text { vs control }\end{array}$ \\
\hline Mycko & 2003 & White matter & Clontech Atlas Glass Human 1.0 & Margin/centre - active/silent lesions \\
\hline Graumann & 2003 & White matter & Clontech Atlas cDNA Expression Array & normal-appearing vs control \\
\hline Lindberg & 2004 & White matter & Affymetrix U95A & $\begin{array}{l}\text { normal-appearing and active } \\
\text { lesions vs control }\end{array}$ \\
\hline Dutta & $2006 / 2007$ & Cortex & Affymetrix HG-U133 & MS vs control \\
\hline Zeis & 2008 & White matter & Clontech Atlas cDNA Expression Array & normal-appearing vs control \\
\hline Torkildsen & 2010 & Cortex & $\begin{array}{l}\text { Applied Biosystems } \\
\text { Human Genome Survey Microarray v1.0 }\end{array}$ & $\begin{array}{l}\text { normal-appearing and lesions } \\
\text { vs control }\end{array}$ \\
\hline
\end{tabular}

datasets were stratified by the antiretroviral treatment (ART) status of subjects at the time of death. This approach yielded two distinct HAND brain microarray profiles, one representing untreated patients and consisting of 1,470 dysregulated 
genes and the second representing treated patients and consisting of 253 dysregulated genes, the majority of which were also dysregulated in untreated subjects (Borjabad et al. 2011). To construct the representative HAND brain profile for comparison with $\mathrm{AD}$ and MS profiles, we pooled all datasets listed in Table 1 including transcriptomes from both treated and untreated patients described in Borjabad et al. (Borjabad et al. 2011). This approach was taken because the other HAND studies listed in Table 1 did not provide information on ART status of their patient cohorts and thus they could include either treated, untreated, or both categories of patients. This profile was termed HAND and it was found to consist of (excluding multiply listed genes, see Methods) 1,132 up-regulated and 779 down-regulated HANDassociated genes (Table 1).

Because ART clearly mitigated cellular gene expression in the brain of patients with HAND compared to that in untreated patients (Borjabad et al. 2011), we designated a second category of HAND transcriptomes called ARTHAND which contained only datasets of HAND patients known to be on treatment prior to death. Patients in this category, in a single study published so far, continued to manifest cognitive disease in the last evaluation prior to death (Borjabad et al. 2011). These results were interpreted as being indicative of fundamental gene expression changes in the brain leading to HAND (Borjabad et al. 2011) and they could possibly be involved in AD and MS as well. The ART-HAND dataset contains 128 significantly up-regulated and 125 down-regulated genes (Borjabad et al. 2011).

\section{Transcriptome profiles in AD and MS}

Table 2 lists microarray studies in AD and MS brain tissues selected for comparison with HAND transcriptomes. The criteria for study selection are described in Methods and below. The Table also provides information on the anatomical brain region and microarray platform used, and the biological states compared in each study. AD is at present the most common form of dementia including progressive memory loss, decline in cognitive functions, and other behavioral symptoms. Gene and protein changes in AD have been extensively studied and numerous functional genomics analyses have also been reported including studies in animal models of AD (Jee et al. 2007; Prinzen et al. 2009; Tseveleki et al. 2010), isolated brain cells (Counts et al. 2007; Ginsberg et al. 2010), and post-mortem human brain tissue. In human $\mathrm{AD}$ brain, the main areas of analysis are the cortex (Pasinetti 2001; Walker et al. 2004; Emilsson et al. 2006) and hippocampus (Colangelo et al. 2002; Blalock et al. 2004; Brooks et al. 2007), two areas implicated in the pathobiology of AD. Other studies analyzed and compared different areas of the brain (Grunblatt et al. 2007; Katsel et al. 2007; Parachikova et al. 2007), or focused on specific molecules and treatments (for review of $\mathrm{AD}$ functional genomic studies see (Katsel et al. 2005)). Given the large number of microarray studies in AD brain tissues, we selected 18 analyses of cortex and hippocampus representing a broad scope of AD conditions studied, including comparisons of $\mathrm{AD}$ stages, different $\mathrm{AD}$ pathologies, $\mathrm{AD}$ in young vs. old individuals, and others (Table 2). The studies used a variety of microarray platforms including those from Incyte Pharmaceuticals, Incyte Genomics, Clontech, Agilent, and Affymetrix, and others (Table 2). Only studies containing complete microarray analysis and data in format suitable for this meta-analysis were selected. The microarray datasets from the selected AD studies were pooled and multiply listed genes were excluded, yielding what we define here as the representative $\mathrm{AD}$ transcriptome profile. This profile contained 5,185 up-regulated and 3,684 down-regulated genes (Table 2).

MS is a chronic inflammatory disease of the central nervous system mainly affecting white matter in which autoreactive $\mathrm{T}$ cells attack the myelin-oligodendrocyte complex (for review see (Noseworthy et al. 2000)). Several microarray studies employed mouse models of MS or cells (for reviews see (Steinman and Zamvil 2003; Mix et al. 2010)); in addition a large number of studies evaluated gene expression in human brain tissue from patients with MS (for review see (Lindberg and Kappos 2006; Tajouri et al. 2007; Kinter et al. 2008; Dutta and Trapp 2010)). These investigations involved both white (Graumann et al. 2003; Tajouri et al. 2003; Lindberg et al. 2004) and grey matter (Dutta et al. 2006; Dutta et al. 2007; Torkildsen et al. 2010). Some of these studies analyzed genes altered in acute, chronic or silent lesions or normal tissue. For the present meta-analysis we selected nine representative sets of genes from papers listed in Table 2. Similar to AD studies, a wide variety of microarray platforms were used. The microarray datasets from all nine studies were pooled and multiply listed genes were excluded, yielding what we define here as the MS transcriptome profile; this profile consisted of 3,922 up-regulated and 4,171 down-regulated genes (Table 2).

Two-way analysis of an overlap in gene and biological process dysregulation between HAND and AD and HAND and MS

The transcriptome profiles of HAND and ART-HAND were each compared pairwise with $\mathrm{AD}$ and MS transcriptomes (Table 3). A substantial number of dysregulated HAND genes in both HAND groups were also dysregulated in $\mathrm{AD}$ and MS profiles, with the actual number of common changes depending in part upon the number of genes present in the groups tested (Table 3). The individual lists of genes in these groups, including Gene Symbol, Gene Title, and the gene ontology annotations: "Entrez Gene ID" from NCBI and "GO ID" from the Gene Ontology (GO) Consortium, are provided under separate tabs in Online Resource 1. A total of 
Table 3 Number and percentage of dysregulated genes in brain tissues of HAND or ART-HAND in common with AD or MS

\begin{tabular}{|c|c|c|c|c|c|c|c|c|c|c|c|c|}
\hline & \multicolumn{6}{|c|}{ Alzehimer's disease ( 8,869 genes $)$} & \multicolumn{6}{|c|}{ Multiple sclerosis ( 8,093 genes) } \\
\hline & All & & Up & & Down & & All & & Up & & Do & \\
\hline HAND (1911 genes) & 665 & $35 \%$ & 381 & $34 \%$ & 284 & $36 \%$ & 254 & $13 \%$ & 170 & $15 \%$ & 84 & $11 \%$ \\
\hline ART-HAND (253 genes) & 49 & $19 \%$ & 36 & $28 \%$ & 13 & $10 \%$ & 43 & $17 \%$ & 21 & $16 \%$ & 22 & $18 \%$ \\
\hline
\end{tabular}

665 or $35 \%$ of altered genes identified in HAND brain and 49 or $19 \%$ of treated HAND were also dysregulated in AD. The proportion of common up- and down-regulated genes in HAND and $\mathrm{AD}$ was about equal but marked differences were found upon pairing $\mathrm{ART}$-HAND and $\mathrm{AD}$, where the proportions were $28 \%$ and $10 \%$, respectively. The respective frequencies of HAND genes dysregulated in common with MS, 254 out of 1,911 genes or $13 \%$, were much lower than those for HAND/ $\mathrm{AD}$ pairing. Interestingly, however, there were more common down-regulated genes in ART-HAND and MS than in ARTHAND and AD, 22 versus 13, respectively (Table 3).

To confirm the observed commonalities between the HAND, AD, and MS at the single gene level, we performed pairwise (HAND subgroups to AD and HAND subgroups to MS) functional categorization of gene families by EASE (Table 4). The five common most significantly up and down-regulated biological pathways are listed in Table 4; a full list of common dysregulated pathways is provided in Online Resource 2 under category-specific tabs. Consistent with a single-gene analysis, HAND, AD, and MS shared a large number of dysregulated cellular processes; however, in pairwise comparisons the identity, the relative ranking, and the extent of process sharing as indicated by the EASE score were different. For example, while the top four ranking dysregulated processes shared by HAND, AD, and MS were immune response, antigen presentation, and responses to bio- and external stimuli, the statistical significance of pair-wise sharing of these processes reflected in the EASE Score (ES) ranged from $1.36 \times 10^{-30}$ to $2.82 \times 10^{-23}$ for the HAND-AD pair and from $4.97 \times 10^{-07}$ to $1.33 \times 10^{-05}$ for the HAND-MS pair (Table 4 and Online Resource 2). The differences between paired HAND-AD and HAND-MS transcriptomes were even more pronounced for common down-regulated biological pathways. HAND and MS shared only five down-modulated pathways in the brain, all with the low level of statistical significance of just under ES of 0.05. Three of these pathways involved calmodulin, which in the central nervous system is known to regulate processes related to synaptic plasticity (Xia and Storm 2005). In contrast, HAND and AD shared 89 down-regulated processes with ES scores under 0.05; while the five most significant of these also included processes related to synaptic function (i.e., synaptic transmission and synaptic vesicle), their ES scores ranged from $3.48 \times 10^{-12}$ to
$7.59 \times 10^{-10}$. The calmodulin binding pathway was ranked \#8 in the HAND-AD pairing with significance score of $1.75 \times$ $10^{-8}$ whereas this pathway was \#4 in HAND-MS with a score of 0.044 (Table 4 and Online Resource 2).

Consistent with our analysis at the single gene level (Table 3), ART-HAND shared fewer dysregulated biological pathways with $\mathrm{AD}$ and MS and the statistical power of the pathways in common that remained (such as immune response) was also lower (Table 4 and Online Resource 2). The loss of similarity was the greatest for down-modulated biological pathways in paired ART-HAND versus AD analysis, where only four dysregulated pathways remained in common at low significance level (compared to 89 dysregulated pathways in HAND-AD pairing), and none of them representing the highly significant common dysregulation of neuronal functions (Table 4 and Online Resource 2). It should be noted that ART-HAND transcriptomes showed similarly attenuated dysregulation of gene expression when compared to transcriptomes form untreated HAND, a finding that we attributed to the beneficial effects of antiretroviral treatment (Borjabad et al. 2011). There is as yet no treatment alleviating molecular and cognitive symptoms of AD. In this context, because ART-HAND transcriptomes are more similar to those of HIV-negative individuals than people with untreated HAND (Borjabad et al. 2011), the results of comparative analysis of ART-HAND and AD profiles in the present work also can be seen as a specificity control for the HAND-AD comparison.

The analyses presented so far indicate that untreated HAND and $\mathrm{AD}$, more than HAND and MS, share dysfunctions in many "executive" biological pathways responsible for defective neurocognitive functions. To obtain a more detailed view of neuropathobiological mechanisms potentially shared by these patients, we analyzed down-regulated data using gene ontology tool Affymetrix NetAffx ${ }^{\mathrm{TM}}$ Analysis Center (Figs. 1 and 2). Only selected genes are shown; the full lists of aberrant genes used for this analysis are provided under dedicated tags in Online Resource 1 . We found that $61 \%$ of down-regulated pathways shared by HAND and AD were implicated in broadly-defined nervous system functions such as synaptic transmission, nervous system development, and neurocognition processes (Fig. 1). $29 \%$ of shared dysregulated brain processes included genes involved mostly in basic cell- 
Table 4 Five most significant up-regulated (bold) and down-regulated (italic) biological pathways in common in HAND and AD or MS and ARTHAND and AD or MS

\begin{tabular}{|c|c|c|c|c|}
\hline & \multicolumn{2}{|l|}{ Alzheimer's disease } & \multicolumn{2}{|l|}{ Multiple sclerosis } \\
\hline & Gene category & EASE score & Gene category & EASE score \\
\hline \multirow[t]{10}{*}{ HAND } & immune response & $1.36 \mathrm{E}-30$ & response to external stimulus & 4.97E-07 \\
\hline & defense response & $2.25 \mathrm{E}-28$ & immune response & 2.83E-06 \\
\hline & response to biotic stimulus & $3.10 \mathrm{E}-28$ & response to biotic stimulus & 3.63E-06 \\
\hline & response to external stimulus & $2.82 \mathrm{E}-23$ & defense response & 1.33E-05 \\
\hline & antigen presentation & 5.30E-19 & response to stress & 0.0007 \\
\hline & transmission of nerve impulse & $3.48 E-12$ & calmodulin-dependent protein kinase I activity & 0.010 \\
\hline & synaptic transmission & $1.43 E-11$ & non-kinase phorbol ester receptor activity & 0.013 \\
\hline & transport & $1.15 E-10$ & calcium/calmodulin-dependent kinase activity & 0.033 \\
\hline & cell-cell signaling & $2.91 E-10$ & calmodulin binding & 0.045 \\
\hline & synaptic vesicle & $7.59 E-10$ & phorbol ester receptor activity & 0.046 \\
\hline \multirow[t]{10}{*}{ ART-HAND } & antigen presentation & $1.20 \mathrm{E}-05$ & immune response & 0.002 \\
\hline & antigen processing & $1.20 \mathrm{E}-05$ & defense response & 0.003 \\
\hline & signal transducer activity & 7.17E-05 & response to biotic stimulus & 0.005 \\
\hline & immune response & 0.0002 & response to external stimulus & 0.021 \\
\hline & defense response & 0.0004 & antigen processing & 0.022 \\
\hline & DNA helicase activity & 0.018 & intracellular signaling cascade & 0.005 \\
\hline & hydrolase activity & 0.025 & signal transduction & 0.012 \\
\hline & cell growth and/or maintenance & 0.036 & catalytic activity & 0.015 \\
\hline & binding & 0.038 & cell communication & 0.038 \\
\hline & & & cellular process & 0.045 \\
\hline
\end{tabular}

Gene ontology analysis was performed using EASE software (Hosack et al. 2003). The complete list of dysregulated pathways is in Online Resource 2.

physiological functions such as signal transduction and cell cycle, while $10 \%$ of common defective processes remain yet to be defined (Fig. 1). As shown in Fig. 2, the overall distribution of pathway-categorized similarities between HAND and MS was different from that of HAND and AD, with only $37 \%$ (versus $61 \%$ in HAND-AD) of common pathways related to nervous system function and a larger proportion (40\% versus $29 \%$ related to basic cellular processes. Smaller categories (under $10 \%$ ) included calcium transport and metabolism and cell adhesion (Fig. 2). Notably, even within similar broad categories of biological pathways, the majority of aberrant genes identified as common in HAND and MS were different from those common to HAND and $\mathrm{AD}$ (Tables 1 and 2).

Three-way analysis of an overlap in gene and biological process dysregulation between HAND, $\mathrm{AD}$, and MS

The potential pathophysiological overlap between HAND, $\mathrm{AD}$, and MS and ART-HAND, AD, and MS is shown schematically in Venn diagrams in Fig. 3. The diagrams are based on the lists of common dysregulated genes provided in Online Resource 1 . There were 59 up-regulated and 21 downregulated genes in common to HAND, $\mathrm{AD}$, and MS. Gene ontology analysis of these genes (Online Resource 2) revealed common and highly significant up-regulation of immune response processes such as response to external stimulus, inflammation and innate immunity. Other up-regulated pathways included transcription regulation, cell adhesion and others. Only 5 down-regulated pathways scored significantly in all three diseases including neurogenesis in position 5. This result confirms data shown in Table 4 and Figs. 1 and 2 suggesting that the mechanisms of neuronal dysfunction shared between HAND and AD on the one hand and HAND and MS on the other are different. We found only 7 upregulated and 3 down-regulated genes common to ARTHAND, AD, and MS, in part reflecting highly reduced number of dysregulated genes found in ART-treated HAND brain (Borjabad et al. 2011). No significant pathways were found commonly dysregulated in these three groups.

\section{Discussion}

Comparison of gene expression profiles from brain diseases obtained by independent studies is challenging (Glanzer et al. 2004; Lukasiuk and Pitkänen 2004; Higgs et al. 2006; 


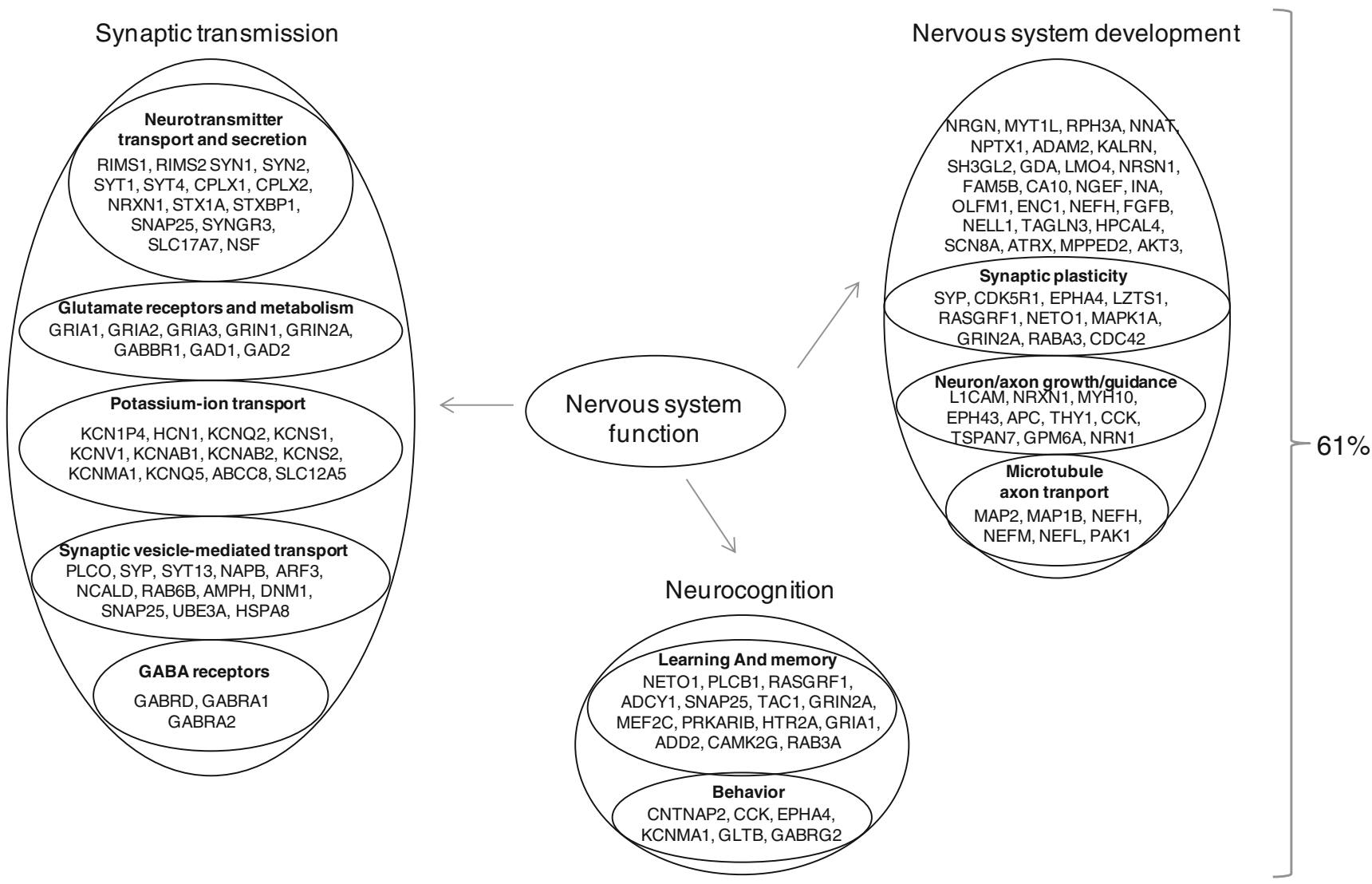

Transcription, signal transduction, translation, DNA/RNA processes, cell cycle, etc

Fig. 1 Common down-regulated genes/pathways in HAND and AD. Down-regulated genes in common in HAND and AD were classified in biological pathways using the Affymetrix NetAffx ${ }^{\mathrm{TM}}$ Analysis Center (http://www.affymetrix.com/analysis/index.affx)

Cooper-Knock et al. 2012). Factors such as the heterogeneity of brain tissue, patient-to-patient variability, disease stage, anatomical location of samples, and technical and study design differences all contribute to a significant variability among individual studies (Glanzer et al. 2004; Lukasiuk and Pitkänen 2004; Higgs et al. 2006; CooperKnock et al. 2012; Hawrylycz et al. 2012). However, variability does not necessarily imply irreproducibility unless the same samples are independently analyzed and yield different results (Sorlie et al. 2003), which was not reported for the array datasets used in the present work. It is likely that individual array analyses for the same disease may represent gene profile snapshots of specific physiological situations tested at different disease stages or different brain anatomical sites, as we recently suggested for transcriptomes of white and grey matter from brain tissues of patients with advanced HAND (Borjabad et al. 2011). With these caveats, we considered such non-overlapping gene expression data from the same disease as cumulative hits of gene dysregulation for inferring tentative representative molecular profiles of HAND, AD, and MS. Having identified specific transcripts modulated in common among these diseases in the present study, future studies can conduct more tailored analysis to compare similar microarray platforms, similar brain regions, patients at similar ages, or sharing other features likely to influence the analysis of the outcome of disease. Such studies have recently been published, for example, for AD and schizophrenia (Park et al. 2012; Roussos et al. 2012) and are under way for HAND in our laboratory.

One major outcome of our analysis is the demonstration of significant similarity between HAND and AD at the brain transcriptome level despite different etiologies of these diseases. HAND is a virally-induced disease in which soluble factors produced by HIV infected/activated macrophages, microglia, and astrocytes induce brain inflammation, disrupt brain homeostasis, mediate neuronal and astrocyte dysfunction, and in advanced disease lead to neuronal and astrocyte apoptosis and dementia (Lipton and Gendelman 1995; Lopez-Villegas et al. 1997; Ellis et al. 2007; Sailasuta et 
Fig. 2 Common downregulated genes/pathways in HAND and MS. Downregulated genes in common in HAND and MS were classified in biological pathways using the Affymetrix NetAffx ${ }^{\text {TM }}$ Analysis Center (http:// www.affymetrix.com/analysis/ index.affx)

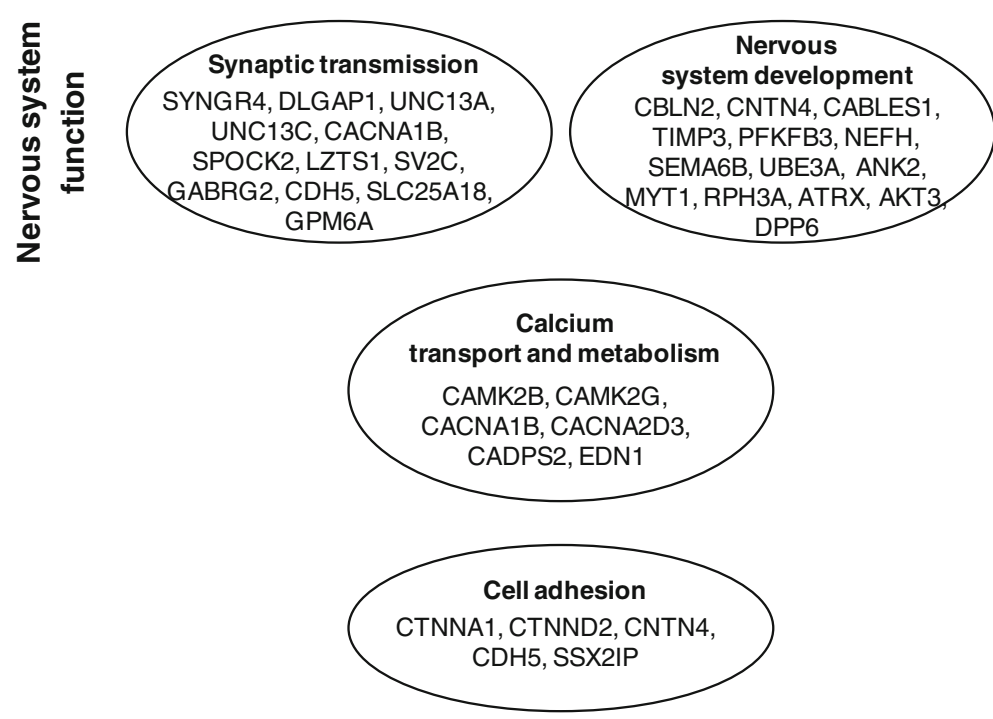

$37 \%$

$9 \%$

$7 \%$

Transcription, signal transduction, translation,

$40 \%$

DNA/RNA processes, cell cycle, etc

Unknown function al. 2009; Borjabad et al. 2011). Thus HAND pathogenesis appears to be driven primarily by environmental insults to neurons and neuronal-astrocyte networks. In contrast, $\mathrm{AD}$ is primarily an auto "proteopathic" (Jucker and Walker 2011) neurodegenerative disease initiated in neurons by misfolding and aggregation of two specific proteins, amyloid-beta and tau, which in later stages of disease form the characteristic lesions of senile plaques and neurofibrillary tangles (Maccioni et al. 2001; Jucker and Walker 2011; Wilcox et al. 2011). Inflammation plays a prominent role in AD but it appears to be secondary to amyloid-beta and tau accumulation (Khandelwal et al. 2011; Zilka et al. 2012). Yet our results suggest that the pathophysiology of HAND and AD converges in a relatively limited number of down-regulated genes responsible for dysfunctions linked to neuronal function and neurodegeneration including synaptic plasticity,
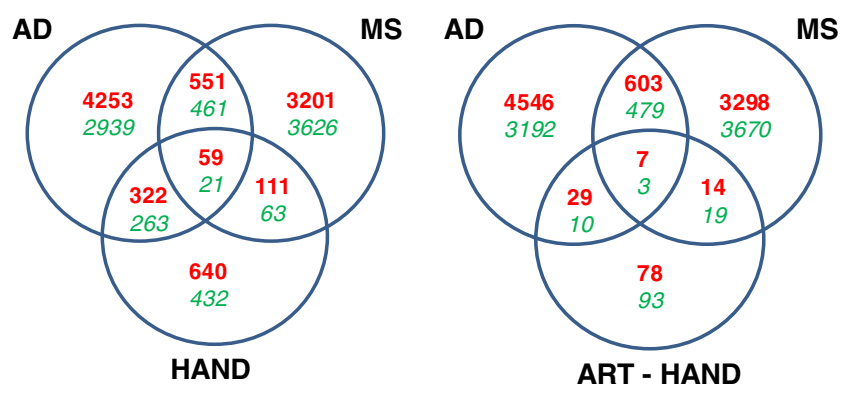

Fig. 3 Common up- (red/bold) and down-regulated (green/italics) genes in HAND, AD, and MS. Venn diagrams show the common number of genes in all three diseases synaptic signal transmission, and axonal transport (Fig. 1). Indeed, synaptodendritic injury and synaptic failure are believed to underlie neurocognitive impairment in both HAND and AD (Selkoe 2002; Ellis et al. 2007; Wilcox et al. 2011). In AD, synaptic failure was correlated with accumulation and post-synaptic binding of beta-amyloid oligomers (Wilcox et al. 2011; Yu and Lu 2012) and accumulation of phosphorylated tau in dendritic spines (Hoover et al. 2010). The mechanisms of synaptic injury in HAND are not fully understood but role of factors secreted by HIVinfected macrophages including HIV Tat protein and platelet-activating factor has been suggested ( $\mathrm{Lu}$ et al. 2007; Lu et al. 2011). Regardless of the proximal stimuli for synaptic injury, these results support the notion that some core cellular processes mediating this impairment in HAND and AD are similar.

In contrast to HAND and AD, while both MS and HAND share pathologies of white matter (Navia et al. 1986b; Noseworthy et al. 2000) they largely diverge in their respective molecular phenotypes of disease. The divergence is consistent with the generally distinct disease phenotypes of HAND and MS; HAND presents cognitive and behavioral impairments with varying motor involvement (Navia et al. 1986a) while MS is mostly known as a debilitating motor and sensory disease (for review see (Noseworthy et al. 2000)). It has been recently recognized that MS also involves cognitive impairment (Noseworthy et al. 2000), and indeed our analysis shows overlap between HAND and MS in dysregulation of genes involved in synaptic calcium processing (Fig. 2). 
Relatively few genes were dysregulated in common in the three diseases analyzed here and they may represent key pathways involved in neurodegeneration. Most prominent among common up-regulated pathways were immune responses, including increased expression of CD14, CD44, MHC class I and II genes HLADQA1 and B2M, interferon response-related genes IRF2 and IL10RB, and complement component C4B (Online Resources 1 and 2). Our analysis extends previous reports on individual gene products and functions (Hoozemans et al. 2011; Reynolds et al. 2011) consistent with the notion that immune responses and chronic neuroinflammation are common denominators of HAND, AD and MS. Also notable was common up-regulation of BACE2, a gene coding for an amyloidbeta peptide that was previously linked to Alzheimer's disease (Holler et al. 2012). Common down-regulated genes in HAND, $\mathrm{AD}$, and MS revealed by our analysis are primarily linked to neuronal and especially synaptic functions consistent with the common neurocognitive impairment in the three diseases (Navia et al. 1986a; Noseworthy et al. 2000; Maccioni et al. 2001), including CBLN2, GPM6A and CUTL2, genes linked to synapse formation and differentiation and implicated in memory processes (Cubelos et al. 2010); neuronal development genes LZTS1 and NAP1L3 (Attia et al. 2011; Kropp and Wilson 2012); and the DDP6 gene that participates in regulation of potassium-related dendritic excitability (Sun et al. 2011). Other common down-regulated genes include calcium-related genes CAMK2G, CACNA2D3 or CADPS2 potentially implicated in the control synaptic plasticity and long term potentiation through sequestration of intracellular calcium (Kawamoto et al. 2012). Of particular interest was suppression of the GABA receptor GABRG2, potentially impairing GABAergic neuron signal transmission and memory (Melzer et al. 2012) and dysregulation of the UBE3A gene that was previously implicated in proteasome degradation and linked to the cognitive impairment of Angelman syndrome (Jiang et al. 2010). Also of note, the three diseases shared down-modulation of hemoglobin B which was recently described as a new marker of neurodegeneration in Alzheimer's disease and other dementias (Ferrer et al. 2011).

Clearly, additional independent analyses with larger datasets and confirmatory RNA and protein assays are needed to substantiate these results. Nevertheless, our work indicates that there might be a core of dysregulated processes in the brain that are common to the three very different neurodegenerative disorders analyzed in the present work. Convergent pathogenic pathways were recently suggested for AD and Huntington's disease (Ehrnhoefer et al. 2011). Better understanding of such putative shared processes of neuropathogenesis may direct development of novel disease prevention strategies and treatments.

Acknowledgments We would like to thank Dr. Mary Jane Potash for her critical review of the manuscript and Ilene M. Totillo for manuscript processing.
Conflict of interest The authors declare that they have no conflict of interest.

Source of funds This work was supported by grants from the National Institutes of Health, US Public Health Service, NS 31492; DA 017618; MH 083627; and NS 061646-01A1.

\section{References}

Alisky JM (2007) The coming problem of HIV-associated Alzheimer's disease. Med Hypotheses 69:1140-1143

Antinori A et al (2007) Updated research nosology for HIV-associated neurocognitive disorders. Neurology 69:1789-1799

Attia M, Förster A, Rachez C, Freemont P, Avner P, Rogner UC (2011) Interaction between nucleosome assembly protein 1-like family members. J Mol Biol 407:647-660

Berger JR, Tornatore C, Major EO, Bruce J, Shapshak P, Yoshioka M, Houff S, Sheremata W, Horton GF, Landy H (1992) Relapsing and remitting human immunodeficiency virus-associated leukoencephalomyelopathy. Ann Neurol 31:34-38

Blalock EM, Geddes JW, Chen KC, Porter NM, Markesbery WR, Landfield PW (2004) Incipient Alzheimer's disease: microarray correlation analyses reveal major transcriptional and tumor suppressor responses. Proc Natl Acad Sci USA 101:2173-2178

Blalock EM, Chen KC, Stromberg AJ, Norris CM, Kadish I, Kraner SD, Porter NM, Landfield PW (2005) Harnessing the power of gene microarrays for the study of brain aging and Alzheimer's disease: statistical reliability and functional correlation. Ageing Res Rev 4:481-512

Borjabad A, Brooks AI, Volsky DJ (2010) Gene expression profiles of HIV-1-infected glia and brain: toward better understanding of the role of astrocytes in HIV-1-associated neurocognitive disorders. J Neuroimmune Pharmacol 5:44-62

Borjabad A, Morgello S, Chao W, Kim S-Y, Brooks AI, Murray J, Potash MJ, Volsky DJ (2011) Significant effects of antiretroviral therapy on global gene expression in brain tissues of patients with HIV-1associated neurocognitive disorders. PLoS Pathog 7:e1002213

Bossers K, Wirz KT, Meerhoff GF, Essing AH, van Dongen JW, Houba P, Kruse CG, Verhaagen J, Swaab DF (2010) Concerted changes in transcripts in the prefrontal cortex precede neuropathology in Alzheimer's disease. Brain 133:3699-3723

Brooks WM, Lynch PJ, Ingle CC, Hatton A, Emson PC, Faull RL, Starkey MP (2007) Gene expression profiles of metabolic enzyme transcripts in Alzheimer's disease. Brain Res 1127:127-135

Colangelo V, Schurr J, Ball MJ, Pelaez RP, Bazan NG, Lukiw WJ (2002) Gene expression profiling of 12633 genes in Alzheimer hippocampal CA1: transcription and neurotrophic factor downregulation and up-regulation of apoptotic and pro-inflammatory signaling. J Neurosci Res 70:462-473

Cooper-Knock J, Kirby J, Ferraiuolo L, Heath PR, Rattray M, Shaw PJ (2012) Gene expression profiling in human neurodegenerative disease. Nat Rev Neurol 8:518-530

Corral I, Quereda C, Garcia-Villanueva M, Casado JL, Perez-Elias MJ, Navas E, Ariza A, Moreno S (2004) Focal monophasic demyelinating leukoencephalopathy in advanced HIV infection. Eur Neurol 52:36-41

Counts SE, He B, Che S, Ikonomovic MD, DeKosky ST, Ginsberg SD, Mufson EJ (2007) Alpha7 nicotinic receptor up-regulation in cholinergic basal forebrain neurons in Alzheimer disease. Arch Neurol 64:1771-1776

Cubelos B, Sebastian-Serrano A, Beccari L, Calcagnotto ME, Cisneros E, Kim S, Dopazo A, Alvarez-Dolado M, Redondo JM, Bovolenta P, Walsh CA, Nieto M (2010) Cux1 and Cux2 regulate 
dendritic branching, spine morphology, and synapses of the upper layer neurons of the cortex. Neuron 66:523-535

D'Agata V, Cavallaro S (2004) Genomic portraits of the nervous system in health and disease. Neurochem Res 29:1201-1212

Dutta R, Trapp BD (2010) Gene expression profiling in multiple sclerosis brain. Neurobiol Dis

Dutta R, McDonough J, Yin X, Peterson J, Chang A, Torres T, Gudz T, Macklin WB, Lewis DA, Fox RJ, Rudick R, Mirnics K, Trapp BD (2006) Mitochondrial dysfunction as a cause of axonal degeneration in multiple sclerosis patients. Ann Neurol 59:478-489

Dutta R, McDonough J, Chang A, Swamy L, Siu A, Kidd GJ, Rudick R, Mirnics K, Trapp BD (2007) Activation of the ciliary neurotrophic factor (CNTF) signalling pathway in cortical neurons of multiple sclerosis patients. Brain 130:2566-2576

Ehrnhoefer DE, Wong BK, Hayden MR (2011) Convergent pathogenic pathways in Alzheimer's and Huntington's diseases: shared targets for drug development. Nat Rev Drug Discov 10:853-867

Ellis R, Langford D, Masliah E (2007) HIV and antiretroviral therapy in the brain: neuronal injury and repair. Nat Rev Neurosci 8:33-44

Emilsson L, Saetre P, Jazin E (2006) Alzheimer's disease: mRNA expression profiles of multiple patients show alterations of genes involved with calcium signaling. Neurobiol Dis 21:618-625

Epstein LG, Sharer LR, Oleske JM, Connor EM, Goudsmit J, Bagdon L, Robert-Guroff M, Koenigsberger MR (1986) Neurologic manifestations of human immunodeficiency virus infection in children. Pediatrics 78:678-687

Everall I, Salaria S, Roberts E, Corbeil J, Sasik R, Fox H, Grant I, Masliah E (2005) Methamphetamine stimulates interferon inducible genes in HIV infected brain. J Neuroimmunol 170:158-171

Everall IP, Salaria S, Atkinson JH, Young C, Corbeil J, Grant I, Masliah E (2006) Diminished somatostatin gene expression in individuals with HIV and major depressive disorder. Neurology 67:1867-1869

Ferrer I, Gomez A, Carmona M, Huesa G, Porta S, Riera-Codina M, Biagioli M, Gustincich S, Aso E (2011) Neuronal hemoglobin is reduced in Alzheimer's disease, argyrophilic grain disease, Parkinson's disease, and dementia with Lewy bodies. J Alzheimers Dis 23:537-550

Gelman BB, Soukup VM, Schuenke KW, Keherly MJ, Holzer C 3rd, Richey FJ, Lahart CJ (2004) Acquired neuronal channelopathies in HIV-associated dementia. J Neuroimmunol 157:111-119

Ginsberg SD, Alldred MJ, Counts SE, Cataldo AM, Neve RL, Jiang Y, Wuu J, Chao MV, Mufson EJ, Nixon RA, Che S (2010) Microarray analysis of hippocampal CA1 neurons implicates early endosomal dysfunction during Alzheimer's disease progression. Biol Psychiatry 68:885-893

Glanzer JG, Haydon PG, Eberwine JH (2004) Expression profile analysis of neurodegenerative disease: advances in specificity and resolution. Neurochem Res 29:1161-1168

Graumann U, Reynolds R, Steck AJ, Schaeren-Wiemers N (2003) Molecular changes in normal appearing white matter in multiple sclerosis are characteristic of neuroprotective mechanisms against hypoxic insult. Brain Pathol 13:554-573

Grunblatt E (2004) The benefits of microarrays as tools for studying neuropsychiatric disorders. Drugs Today (Barc) 40:147-156

Grunblatt E, Zander N, Bartl J, Jie L, Monoranu CM, Arzberger T, Ravid R, Roggendorf W, Gerlach M, Riederer P (2007) Comparison analysis of gene expression patterns between sporadic Alzheimer's and Parkinson's disease. J Alzheimers Dis 12:291-311

Harezlak J, Buchthal S, Taylor M, Schifitto G, Zhong J, Daar E, Alger J, Singer E, Campbell T, Yiannoutsos C, Cohen R, Navia B (2011) Persistence of HIV-associated cognitive impairment, inflammation, and neuronal injury in era of highly active antiretroviral treatment. AIDS 25:625-633

Hawrylycz MJ et al (2012) An anatomically comprehensive atlas of the adult human brain transcriptome. Nature 489:391-399
Heaton RK et al (2010) HIV-associated neurocognitive disorders persist in the era of potent antiretroviral therapy: CHARTER Study. Neurology 75:2087-2096

Higgs BW, Elashoff M, Richman S, Barci B (2006) An online database for brain disease research. BMC Genomics 7:70

Hoheisel JD (2006) Microarray technology: beyond transcript profiling and genotype analysis. Nat Rev Genet 7:200-210

Holler CJ, Webb RL, Laux AL, Beckett TL, Niedowicz DM, Ahmed RR, Liu Y, Simmons CR, Dowling AL, Spinelli A, Khurgel M, Estus S, Head E, Hersh LB, Murphy MP (2012) BACE2 expression increases in human neurodegenerative disease. Am J Pathol 180:337-350

Hoover BR, Reed MN, Su J, Penrod RD, Kotilinek LA, Grant MK, Pitstick R, Carlson GA, Lanier LM, Yuan LL, Ashe KH, Liao D (2010) Tau mislocalization to dendritic spines mediates synaptic dysfunction independently of neurodegeneration. Neuron 68:1067-1081

Hoozemans JJM, Rozemuller AJM, van Haastert ES, Eikelenboom P, van Gool WA (2011) Neuroinflammation in Alzheimer's disease wanes with age. J Neuroinflammation 8:171

Hosack DA, Dennis G Jr, Sherman BT, Lane HC, Lempicki RA (2003) Identifying biological themes within lists of genes with EASE. Genome Biol 4:R70

Jee SW, Cho JS, Kim CK, Hwang DY, Shim SB, Lee SH, Sin JS, Kim YS, Park JH, Choi SY, Kim YK (2007) Analysis of differentially expressed genes in early- and late-stage APPsw-transgenic and normal mice using cDNA microarray. Int J Mol Med 19:461-468

Jiang YH, Pan Y, Zhu L, Landa L, Yoo J, Spencer C, Lorenzo I, Brilliant M, Noebels J, Beaudet AL (2010) Altered ultrasonic vocalization and impaired learning and memory in Angelman syndrome mouse model with a large maternal deletion from Ube3a to Gabrb3. PLoS One 5:e12278

Jucker M, Walker LC (2011) Pathogenic protein seeding in Alzheimer disease and other neurodegenerative disorders. Ann Neurol 70:532-540

Katsel PL, Davis KL, Haroutunian V (2005) Large-scale microarray studies of gene expression in multiple regions of the brain in schizophrenia and Alzheimer's disease. Int Rev Neurobiol 63:41-82

Katsel P, Li C, Haroutunian V (2007) Gene expression alterations in the sphingolipid metabolism pathways during progression of dementia and Alzheimer's disease: a shift toward ceramide accumulation at the earliest recognizable stages of Alzheimer's disease? Neurochem Res 32:845-856

Kawamoto EM, Vivar C, Camandola S (2012) Physiology and pathology of calcium signaling in the brain. Front Pharmacol 3:61

Khandelwal PJ, Herman AM, Moussa CE (2011) Inflammation in the early stages of neurodegenerative pathology. J Neuroimmunol 238:1-11

Kinter J, Zeis T, Schaeren-Wiemers N (2008) RNA profiling of MS brain tissues. Int MS J 15:51-58

Kropp M, Wilson SI (2012) The expression profile of the tumor suppressor gene Lzts1 suggests a role in neuronal development. Dev Dyn 241:984-994

Lackner P, Kuenz B, Reindl M, Morandell M, Berger T, Schmutzhard E, Eggers C (2010) Antibodies to myelin oligodendrocyte glycoprotein in HIV-1 associated neurocognitive disorder: a crosssectional cohort study. J Neuroinflammation 7:79

Lindberg RL, Kappos L (2006) Transcriptional profiling of multiple sclerosis: towards improved diagnosis and treatment. Expert Rev Mol Diagn 6:843-855

Lindberg RL, De Groot CJ, Certa U, Ravid R, Hoffmann F, Kappos L, Leppert D (2004) Multiple sclerosis as a generalized CNS disease-comparative microarray analysis of normal appearing white matter and lesions in secondary progressive MS. J Neuroimmunol 152:154-167 
Lipton S, Gendelman HE (1995) Dementia associated with the acquired immunodeficiency syndrome. N Engl J Med 233:934-940

Lopez-Villegas D, Lenkinski RE, Frank I (1997) Biochemical changes in the frontal lobe of HIV-infected individuals detected by magnetic resonance spectroscopy. Proc Natl Acad Sci USA 94:98549859

Lu SM, Tong N, Gelbard HA (2007) The phospholipid mediator platelet-activating factor mediates striatal synaptic facilitation. $\mathrm{J}$ Neuroimmune Pharmacol 2:194-201

Lu SM, Tremblay ME, King IL, Qi J, Reynolds HM, Marker DF, Varrone JJ, Majewska AK, Dewhurst S, Gelbard HA (2011) HIV-1 Tat-induced microgliosis and synaptic damage via interactions between peripheral and central myeloid cells. PLoS One 6: e23915

Lukasiuk K, Pitkänen A (2004) Large-scale analysis of gene expression in epilepsy research: is synthesis already possible? Neurochem Res 29:1169-1178

Maccioni RB, Munoz JP, Barbeito L (2001) The molecular bases of Alzheimer's disease and other neurodegenerative disorders. Arch Med Res 32:367-381

Masliah E, Roberts ES, Langford D, Everall I, Crews L, Adame A, Rockenstein E, Fox HS (2004) Patterns of gene dysregulation in the frontal cortex of patients with HIV encephalitis. J Neuroimmunol 157:163-175

Melzer S, Michael M, Caputi A, Eliava M, Fuchs EC, Whittington MA, Monyer H (2012) Long-range-projecting GABAergic neurons modulate inhibition in hippocampus and entorhinal cortex. Science 335:1506-1510

Minagar A, Shapshak P, Fujimura R, Ownby R, Heyes M, Eisdorfer C (2002) The role of macrophage/microglia and astrocytes in the pathogenesis of three neurologic disorders: HIV-associated dementia, Alzheimer disease, and multiple sclerosis. J Neurol Sci 202:13-23

Minagar A, Shapshak P, Duran EM, Kablinger AS, Alexander JS, Kelley RE, Seth R, Kazic T (2004) HIV-associated dementia, Alzheimer's disease, multiple sclerosis, and schizophrenia: gene expression review. J Neurol Sci 224:3-17

Mix E, Meyer-Rienecker H, Hartung HP, Zettl UK (2010) Animal models of multiple sclerosis-potentials and limitations. Prog Neurobiol 92:386-404

Navia BA, Price RW (1987) The acquired immunodeficiency syndrome dementia complex as the presenting or sole manifestation of human immunodeficiency virus type infection. Arch Neurol 44:65-69

Navia BA, Jordan BD, Price RW (1986a) The AIDS dementia complex: I. Clinical features. Ann Neurol 19:517-524

Navia BA, Cho ES, Petito CK, Price RW (1986b) The AIDS dementia complex: II. Neuropathology. Ann Neurol 19:525-535

Noorbakhsh F, Overall CM, Power C (2009) Deciphering complex mechanisms in neurodegenerative diseases: the advent of systems biology. Trends Neurosci 32:88-100

Noseworthy JH, Lucchinetti C, Rodriguez M, Weinshenker BG (2000) Multiple sclerosis. N Engl J Med 343:938-952

Parachikova A, Agadjanyan MG, Cribbs DH, Blurton-Jones M, Perreau V, Rogers J, Beach TG, Cotman CW (2007) Inflammatory changes parallel the early stages of Alzheimer disease. Neurobiol Aging 28:1821-1833

Park B, Lee W, Han K (2012) Modeling the interactions of Alzheimer-related genes from the whole brain microarray data and diffusion tensor images of human brain. BMC Bioinforma 13(Suppl 7):S10

Parmigiani G, Garrett-Mayer ES, Anbazhagan R, Gabrielson E (2004) A cross-study comparison of gene expression studies for the molecular classification of lung cancer. Clin Cancer Res 10:2922-2927
Pasinetti GM (2001) Use of cDNA microarray in the search for molecular markers involved in the onset of Alzheimer's disease dementia. J Neurosci Res 65:471-476

Prinzen C, Trumbach D, Wurst W, Endres K, Postina R, Fahrenholz F (2009) Differential gene expression in ADAM10 and mutant ADAM10 transgenic mice. BMC Genomics 10:66

Pulliam L (2009) HIV regulation of amyloid beta production. J Neuroimmune Pharmacol 4:213-217

Rempel HC, Pulliam L (2005) HIV-1 Tat inhibits neprilysin and elevates amyloid beta. AIDS 19:127-135

Reynolds R, Roncaroli F, Nicholas R, Radotra B, Gveric D, Howell O (2011) The neuropathological basis of clinical progression in multiple sclerosis. Acta Neuropathol 122:155-170

Richman DD (2001) HIV chemotherapy. Nature 410:995-1001

Robertson KR, Smurzynski M, Parsons TD, Wu K, Bosch RJ, Wu J, McArthur JC, Collier AC, Evans SR, Ellis RJ (2007) The prevalence and incidence of neurocognitive impairment in the HAART era. AIDS 21:1915-1921

Roussos P, Katsel P, Davis KL, Siever LJ, Haroutunian V (2012) A system-level transcriptomic analysis of schizophrenia using postmortem brain tissue samples. Arch Gen Psychiatry 1-11

Sacktor N, McDermott MP, Marder K, Schifitto G, Selnes OA, McArthur JC, Stern Y, Albert S, Palumbo D, Kieburtz K, De Marcaida JA, Cohen B, Epstein L (2002) HIV-associated cognitive impairment before and after the advent of combination therapy. J Neurovirol 8:136-142

Sailasuta N, Shriner K, Ross B (2009) Evidence of reduced glutamate in the frontal lobe of HIV-seropositive patients. NMR Biomed $22: 326-331$

Salaria S, Badkoobehi H, Rockenstein E, Crews L, Chana G, Masliah E, Everall IP (2007) Toll-like receptor pathway gene expression is associated with human immunodeficiency virus-associated neurodegeneration. J Neurovirol 13:496-503

Selkoe DJ (2002) Alzheimer's disease is a synaptic failure. Science 298:789-791

Shapshak P, Duncan R, Torres-Muñoz JE, Duran EM, Minagar A, Petito CK (2004) Analytic approaches to differential gene expression in AIDS versus control brains. Front Biosci 9:2935-2946

Shapshak P, Rodriguez HE, Kayathri R, Levine A, Chiappelli F, Minagar A (2008) Alzheimer's disease and HIV associated dementia related genes: I. location and function. Bioinformation 2:348-357

Simioni S, Cavassini M, Annoni JM, Rimbault Abraham A, Bourquin I, Schiffer V, Calmy A, Chave JP, Giacobini E, Hirschel B, Du Pasquier RA (2010) Cognitive dysfunction in HIV patients despite long-standing suppression of viremia. AIDS 24:1243-1250

Sorlie T, Tibshirani R, Parker J, Hastie T, Marron JS, Nobel A, Deng S, Johnsen H, Pesich R, Geisler S, Demeter J, Perou CM, Lonning PE, Brown PO, Borresen-Dale AL, Botstein D (2003) Repeated observation of breast tumor subtypes in independent gene expression data sets. Proc Natl Acad Sci USA 100:8418-8423

Steinman L, Zamvil S (2003) Transcriptional analysis of targets in multiple sclerosis. Nat Rev Immunol 3:483-492

Stephens EB, Jackson M, Cui L, Pacyniak E, Choudhuri R, Liverman CS, Salomon DS, Berman NE (2006) Early dysregulation of cripto-1 and immunomodulatory genes in the cerebral cortex in a macaque model of neuroAIDS. Neurosci Lett 410:94-99

Sun W, Maffie JK, Lin L, Petralia RS, Rudy B, Hoffman DA (2011) DPP6 establishes the A-type $\mathrm{K}(+)$ current gradient critical for the regulation of dendritic excitability in CA1 hippocampal neurons. Neuron 71:1102-1115

Tajouri L, Mellick AS, Ashton KJ, Tannenberg AE, Nagra RM, Tourtellotte WW, Griffiths LR (2003) Quantitative and qualitative changes in gene expression patterns characterize the activity of plaques in multiple sclerosis. Brain Res Mol Brain Res 119: 170 183 
Tajouri L, Fernandez F, Griffiths LR (2007) Gene expression studies in multiple sclerosis. Curr Genomics 8:181-189

Tan PK, Downey TJ, Spitznagel EL Jr, Xu P, Fu D, Dimitrov DS, Lempicki RA, Raaka BM, Cam MC (2003) Evaluation of gene expression measurements from commercial microarray platforms. Nucl Acids Res 31:5676-5684

Torkildsen O, Stansberg C, Angelskar SM, Kooi EJ, Geurts JJ, van der Valk P, Myhr KM, Steen VM, Bo L (2010) Upregulation of immunoglobulin-related genes in cortical sections from multiple sclerosis patients. Brain Pathol 20:720-729

Tseveleki V, Rubio R, Vamvakas SS, White J, Taoufik E, Petit E, Quackenbush J, Probert L (2010) Comparative gene expression analysis in mouse models for multiple sclerosis, Alzheimer's disease and stroke for identifying commonly regulated and disease-specific gene changes. Genomics 96:82-91

Walker PR, Smith B, Liu QY, Famili AF, Valdes JJ, Liu Z, Lach B (2004) Data mining of gene expression changes in Alzheimer brain. Artif Intell Med 31:137-154
Wilcox KC, Lacor PN, Pitt J, Klein WL (2011) Abeta oligomerinduced synapse degeneration in Alzheimer's disease. Cell Mol Neurobiol 31:939-948

Xia Z, Storm DR (2005) The role of calmodulin as a signal integrator for synaptic plasticity. Nat Rev Neurosci 6:267-276

Yu W, Lu B (2012) Synapses and dendritic spines as pathogenic targets in Alzheimer's disease. Neural Plast 2012:247150

Zhou L, Diefenbach E, Crossett B, Tran SL, Ng T, Rizos H, Rua R, Wang B, Kapur A, Gandhi K, Brew BJ, Saksena NK (2010) First evidence of overlaps between HIV-Associated Dementia (HAD) and non-viral neurodegenerative diseases: proteomic analysis of the frontal cortex from HIV+ patients with and without dementia. Mol Neurodegener 5:27

Zilka N, Kazmerova Z, Jadhav S, Neradil P, Madari A, Obetkova D, Bugos O, Novak M (2012) Who fans the flames of Alzheimer's disease brains? Misfolded tau on the crossroad of neurodegenerative and inflammatory pathways. J Neuroinflammation 9:47 